\title{
Effects of Sub-Lethal Concentration of Cypermethrin on Histopathological and Hematological Profile of Rohu (Labeo rohita) during Acute Toxicity
}

\author{
Nasir Khan ${ }^{1}$, Munawar Saleem Ahmad ${ }^{2}$, Sadia Tabassam ${ }^{1}$, Faisal Nouroz ${ }^{3}$, Ashfaq Ahmad ${ }^{4}$ and Shehzad Ghayyur ${ }^{4}$, \\ Atta Ur Rehman ${ }^{1}$ and Muhammad Fiaz Khan ${ }^{1 *}$ \\ ${ }^{1}$ Department of Zoology, Hazara University, Mansehra, Pakistan \\ ${ }^{2}$ Department of Zoology, University of Swabi, Swabi, Pakistan \\ ${ }^{3}$ Department of Botany, Hazara University, Mansehra, Pakistan \\ ${ }^{4}$ Government Postgraduate College Haripur, KPK Pakistan \\ *For correspondence: fiazkhanhu333@gmail.com
}

\begin{abstract}
The present investigation was designed to understand the lethal effects of Cypermethrin (CYP); an active pyrethroid, a widely used against an extensive range of pests in agriculture. In this study, Rohu (Labeo rohita Hamilton) was subjected to the treatment with three sub-lethal concentrations $(0.50,1.00$ and $1.5 \mathrm{ppb})$ of CYP for a total period of $96 \mathrm{~h}$. The results obtained indicated significant stress in the studied fish due to pesticide intoxication. Pronounced effects of CYP on fish hematology included significant increase $(\mathrm{p}<0.05)$ in white blood cells (WBCs), platelets and blood glucose level in treated group compared to control group. Conversely; however, substantial decrease in red blood cells (RBCs), hemoglobin (Hb) level, hematocrit (HCT), mean corpuscular volume (MCV), mean corpuscular hemoglobin (MCH) and mean corpuscular hemoglobin concentration (MCHC) was noticed among the treated group related to control group $(\mathrm{p}<0.05)$. Similarly, the histopathological lesions in the gills of exposed fish included lamellar disorder, disruption of cartilaginous core, epithelial lifting, blood mobbing, damage to secondary lamellae, fusion of secondary gills lamellae, twisting and shortening of secondary gills lamellae and degeneration and atrophy. While liver exhibited dissolution of cell membrane, Pyknosis, blood congestion, necrosis, hyperplasia and vacuolations; intestine was characterized by symptoms like necrosis, hemorrhages, over production of goblet cells in villi, disintegration, fusion and shortening of villi. In summary, we reported marked impacts of CYP on both hematological and histopathological traits of $L$. rohita. These, findings warrant that the indiscriminate use of CYP significantly increased WBCs, platelets and blood glucose level whereas it decreased RBCs, Hb, HCT, MCV, MCH and MCHC respectively. It also significantly affected the histopathology such as disruption of gills, liver and intestine architecture. (C) 2018 Friends Science Publishers
\end{abstract}

Keywords: Pesticides; Cypermethrin toxicity; Labeo rohita; Pakistan

\section{Introduction}

The use of pesticides is a common practice in agriculture in recent era owing to the increasing demand of food requirements. Nevertheless, the use of pesticide has resulted in contamination of the environment with far-reaching consequences for living organisms. For instance, only $0.1 \%$ of the total applied pesticides reach the pests while remaining $99.9 \%$ find their way to alter the components of environment (Marigoudar et al., 2009). Organophosphorus compounds were commonly used in industries, medicines and agriculture (Amin and Hashem, 2012). However; until recently this pesticide is continuously substituted with pyrethroids owing to their greater photo stability, less toxicity in birds as well as mammals, greater efficiency even in low concentration, and easy to disintegrate (Bradbury and Coats, 1989). The pyrethroids, are decidedly toxic to fish with little capacity to neutralize and hydrolyze such compounds (Haya, 1989). Therefore, the core cause of elevated toxicity for fish aquaculture are the pesticides from farming fields brought with rain into coves, ponds and rivers. Another possible source of this contamination may be the phytoplanktons (Das and Mukherjee, 2003). Pyrethroids are proved to possess an elevated degree of gill absorption even at very low concentrations in the water and this has been contributed to their lipophilicity which in turn causes sensitivity in fish to aqueous pyrethroid exposure due to low rate of pyrethroids metabolism (Viran et al., 2003).

Cypermethrin (CYP), a synthetic pyrethroid, is one of the most effective insecticide used in forestry, agriculture,

To cite this paper: Khan, N., S. Tabassam, M.S. Ahmad, F. Norouz, A. Ahmad, S. Ghayyur, A.U. Rehman and M.F. Khan, 2018. Effects of sub-lethal concentration of cypermethrin on histopathological and hematological profile of rohu (Labeo rohita) during acute toxicity. Int. J. Agric. Biol., 20: 601-608 
buildings and farmyards (Casida et al., 1983; Khan et al., 2006). Commercially CYP is being used against cotton and soybean pests (Carriquiriborde et al., 2007). The use of CYP is increasing day by day in the world for fishing. In addition, some aqua culturists also use CYP as a chemotherapeutic agent to eradicate different copepod infestations (Medina et al., 2002; Athanassopoulou et al., 2009; Nafees and Jan, 2009). Consequently, CYP due to its diffusion and surface runoff into natural water reservoirs, seemed as a main hazard to the aquatic fauna including fishes (John and Prakash, 2003).

Besides its well-developed nervous, immune, endocrine and osmoregulatory systems, fish species exhibit high sensitivity to fluctuations in external environment and is capable of bio-accumulating toxic materials in higher concentration relating to surrounding water. These attributes favored the fish to be used as an important eco-toxicological biomarker and suitable bio-indicator as compared to other vertebrates and invertebrates (Song et al., 2012; Huang et al., 2013; Eagles-Smith and Ackerman, 2014; Dhanakumar et al., 2015; Zhao et al., 2016). The pesticides accumulation in the important organs, including liver and muscles may leads to organ dysfunction resulting in demise of the fish. Similarly, efficiency of some enzymes indispensable for metabolic purposes of fish may be altered (Srivastava and Kaushik, 2001).

In Pakistan, CYP is being used extensively for a variety of purposes including, but not limited to, pest control of different crops, fruits and vegetables and illegitimate fishing (Khan et al., 2006; Nafees and Jan, 2009). Around the world, it is being used in aquaculture as a chemotherapeutic agent against lice infiltration and preventing invasion by copepod parasites (Boxaspen and Holm, 2001; Barata et al., 2002; Medina et al., 2002). Thus, use of CYP on commercial level could cause ecological toxicity in water reservoirs, which in turn could have adverse implications on the aquatic biota generally and fish particularly (John and Prakash, 2003). The current investigation was undertaken to investigate the sub lethal effect of CYP on certain hematological and histopathological parameters of Labeo rohita Hamilton.

\section{Materials and Methods}

\section{Physico-chemical Parameters of Water}

The physico-chemical parameters of test water used in this experiment were: Temperature $\left(21 \pm 1.19^{\circ} \mathrm{C}\right)$; $\mathrm{PH}(7.5 \pm 0.23)$; total dissolved solids $(366 \pm 10.81 \mathrm{mg} / \mathrm{L})$; dissolved oxygen $(6.4 \pm 0.53 \mathrm{mg} / \mathrm{L})$; total alkalinity $(129 \pm 4.89 \mathrm{mg} / \mathrm{L})$; calcium hardness $(44 \pm 1.55 \mathrm{mg} / \mathrm{L})$; chloride $(18.5 \pm 2.1 \mathrm{mg} / \mathrm{L})$ and conductivity $(819 \pm 14.9 \mathrm{mS} / \mathrm{cm})$.

\section{Fish Collection and Acclimatization}

A total of thirty Rohu fish (Labeo rohita Hamilton) with a body weight $(336.25 \pm 28.53 \mathrm{~g})$ were collected from Abdul
Wahid fish farm Punjab and were transferred to the dechlorinated fresh-water reservoir under controlled temperature where they were kept for at least three days and were fasted for $24 \mathrm{~h}$ before embarking the experiments. The fish were then soaked for a few seconds in $0.2 \% \mathrm{~K}_{2} \mathrm{MnO}_{4}$ solution followed by washing with tap water. Fish were then left to adapt to laboratory environment for about a week preceding the onset of trials. They were kept in aerated glass aquarium filled with dechlorinated tap water having a temperature of $20-23^{\circ} \mathrm{C}, \mathrm{pH} 7.6-7.8$ and $100 \%$ dissolved oxygen. During this retro, fish were fed daily with commercial food. The residual food was eliminated after serving. Around $70 \%$ of the water was changed each day during acclimatization period.

\section{Study Design}

Cypermethrin ([S, R]-N- $\alpha$-cyno-3-phenoxybenzyl-(IR, IS, cis, trans)-2, 2-dimethyl-3, (2, 2-dichlorovinyl, cyclopropane carboxylate), used in this study was purchased from a local market of Haripur, Khyber Pakhtunkhwa, Pakistan. So as to assess the impacts of CYP on L. rohita, test solutions of three varying concentrations i.e., $0.50 \mathrm{ppb}$, $1.00 \mathrm{ppb}$ and $1.50 \mathrm{ppb}$ of CYP were formulated from a commercial devising carrying $32 \%$ active ingredients. Randomly selected Five fishes were stocked in each of the four aquaria of $80 \mathrm{~L}$ water capacity which were half filled. Each of the tank was provided with different concentration of CYP and were labeled as, E0, E1, E2 and E3. E0 had zero concentration of CYP and considered as control group, E1 had $0.50 \mathrm{ppb}$, E2 had $1.00 \mathrm{ppb}$ while E3 had $1.50 \mathrm{ppb}$ CYP. Fishes were exposed to CYP for $96 \mathrm{~h}$ and tested solutions were renewed after $24 \mathrm{~h}$ throughout the experiment.

\section{Hematological and Biochemical Effects of CYP}

For studying hematological, blood samples were collected from each fish in EDTA containing tubes. The blood samples were analyzed using HEMA READER HRG 6300D (auto hematological analyzer Advanced Japanese Technology, China). The hematological parameters checked in this study included total red blood cell count, hemoglobin content, total white blood cell count and hematocrit level. Likewise, the corpuscular indices comprised mean corpuscular volume (MCV), mean corpuscular hemoglobin $(\mathrm{MCH})$ and mean corpuscular hemoglobin concentration (MCHC).

\section{Histopathological and Behavioral Effects of CYP}

For biochemical analysis, the clotted tubes carrying blood samples were spun for separation of plasma from blood cells. Plasma was collected and glucose level was determined by using Chem Reader SBA-733 Plus (Semiauto Chemistry analyzer, Advanced Japanese Technology). 
For histopathological analysis, each fish was weighed on a digital balance. Moreover, for measurements of the total length, standard length and body depth measuring tape was used. The fish were then incised in order to dichotomize the particular biomarker organs including gills, intestine and liver. Each organ was separately weighed and preserved in $10 \%$ neutral buffered formalin (NBF) for $48 \mathrm{~h}$. After fixation, tissues were allowed to dehydrate in ascending succession of alcoholic grades, cleared in xylene and entrenched in paraffin wax. Slices of 4-5 mm thickness were cut on a rotary microtome which were then stained with eosin and hematoxylin and were inspected under a camera fitted microscope, OPTICA TCB 3.0 Italy. Finally, the behavior of $L$. rohita subjected to treatment with different concentration of CYP was recorded during 96-h trial.

\section{Statistical Analysis}

Statistical data analysis was carried out using SPSS software (Version 20.0). Comparison was made among all of the four experimental assemblies using one-way ANOVA. It was then followed by comparison of hematological variables using independent t-test between control and treated groups. Variables were stated as means and standard deviations. $\mathrm{p}<0.05$ was considered as statistically significant.

\section{Results}

\section{Behavioral Effects of CYP}

As a consequence of exposure to CYP, L. rohita showed severe symptoms in all the treated assemblies of fish $(0.5$, 1.00 and $1.50 \mathrm{ppb})$. Several changes in their behavior were observed during acute toxicity. For instance, the distinct changes seen in treated fishes included abnormalities like rapid swimming as fish was added to CYP solution. Furthermore, as the time passed, fishes lost body equilibrium, started swimming at lateral sides, showed high opercular movement, several fishes tried to jump out of aquariums indicating sign of stress, fishes secreted slime, directed their tails downwards and head upwards etc. Control fishes, on the other hand, did not deviated from their normal swimming behavior.

\section{Hematological and Biochemical Effects of CYP}

With CYP exposure, significant changes in the total blood cells count of treated fishes but not the control group were noticed. Overall, WBCs count increased significantly in the treated than control group. Conversely, total RBCs count declined markedly in the treated than control group. Likewise, hemoglobin level also decreased in all the treated groups of fish as compared to control group. While the hematocrit level was significantly decreased in all the three treated groups of fish. The MCV values were increased significantly in all three treated groups. A slight decline was observed in the $\mathrm{MCH}$ level in one treated group compared to control group $(32.82 \pm 0.70)$, the values decreased in two treated groups significantly $\mathrm{p}<0.005$. In contrast with control group, the value of MCHC decreased slightly in two treated groups of fish, while a significant change was noticed in treated group III $(\mathrm{p}<0.05)$. Similarly, the number of platelets increased significantly in treated group compared to control group consistently with the increasing concentration of CYP. Blood glucose level was increased in all three treated groups of fish $(0.50 \mathrm{ppb} 68.2 \pm 0.165, \mathrm{p}<0.05 ; 1.00 \mathrm{ppb} 84.96 \pm 0.250$, $\mathrm{p}<0.05 ; 1.50 \mathrm{ppb} 103.16 \pm 0.248)$ as compared to control group (60.02 \pm 0.191$)$. Thus, comparison of all the treated groups showed significant increase in WBCs, platelets and blood glucose level while a significant reduction in RBCs, $\mathrm{Hb}, \mathrm{HCT}, \mathrm{MCV}, \mathrm{MCH}$, and $\mathrm{MCHC}$ was noticed as the concentration of CYP increased (Table 1).

\section{Histopathological Effects of CYP}

Control gill tissues: Under ordinary light microscope, the gill tissues section of control group of $L$. rohita showed normal assembly of gill filament, primary and secondary gill lamellae having central cartilaginous core and a thin epithelial layer (Table 2). There is a thick lining of stratified epithelium between primary and secondary gill lamellae containing the mucous cells and chloride cells (Fig. 1A-B).

Treated gill tissues: As revealed by histopathological results, CYP primarily targeted gill tissue. For instance, group I treated with $0.50 \mathrm{ppb}$ concentration of CYP showed disruption, fusion and shortening of secondary gills lamellae. In addition, mild blood congestion was also seen (Table 2; Fig. 1C and D). In treated group II and III exposed to $1.00 \mathrm{ppb}$ and $1.50 \mathrm{ppb}$ concentrations of CYP respectively, histopathological changes became more prominent in gills. The changes were shortening, fusion and disruption of secondary gills lamellae, epithelial lifting, and atrophy, disruption of cartilaginous core, blood congestion, lamellar disorganization and curling (Fig. 1E and $\mathrm{H}$ ).

Control liver tissue: When examined with light microscope, liver tissue from control group of L. rohita exhibited normal structure of liver cells (hepatocytes) bearing foamy cytoplasm. Hepatocyte is a roundish polygonal cell body containing a clear spherical nucleus and nucleolus (Table 2; Fig. 2A and B).

Treated liver tissues: In group-I treated with $0.50 \mathrm{ppb}$ of CYP hepatocytes exhibited slight vacuolations, blood congestion, mild pyknosis, dissolution of cell membrane, vacuolations in the hepatocytes (Fig. 2C-D). In group-II treated with $1.00 \mathrm{ppb}$ concentration of CYP, these histopathological variations were moderate in liver (Fig. 2F). In group-III treated with $1.50 \mathrm{ppb}$ of CYP, hepatocytes exhibited pulsating histopathological changes including vacuolations, dissolution of cell membrane, blood congestion, necrosis, pyknosis, and lymphocyte infiltration (Table 2; Fig. 2G-H). 
Khan et al. / Int. J. Agric. Biol., Vol. 20, No. 3, 2018

Table 1: Summarized hematological and biochemical (glucose) parameters of both control and treated groups of rohu

\begin{tabular}{|c|c|c|c|c|}
\hline \multirow[t]{2}{*}{ Hematological and biochemical parameters } & \multirow{2}{*}{$\begin{array}{l}\text { Control group } \\
0.00 \mathrm{ppb}\end{array}$} & \multicolumn{3}{|l|}{ Treated groups } \\
\hline & & T1 (0.50 ppb) & $\mathrm{T} 2(1.00 \mathrm{ppb})$ & $\mathrm{T} 3(1.50 \mathrm{ppb})$ \\
\hline Total WBCs & $78.34 \pm 0.49$ & $79.46 \pm 0.64^{* * \Delta}$ & $89.52 \pm 1.38^{* * \Delta}$ & $97.40 \pm 0.87^{* * \Delta}$ \\
\hline Lymphocytes & $64.56 \pm 0.55$ & $64.52 \pm 0.46^{* * \Delta}$ & $70.40 \pm 0.61^{* * \Delta}$ & $74.76 \pm 0.46^{* * \Delta}$ \\
\hline Neutrophils & $7.20 \pm 0.40$ & $8.08 \pm 0.27^{* * \Delta}$ & $9.92 \pm 0.54^{* * \Delta}$ & $12.86 \pm 0.50^{* * \Delta}$ \\
\hline RBCs & $3.94 \pm 0.14$ & $2.92 \pm 0.07^{* * \Delta}$ & $2.03 \pm 0.06^{* * \Delta}$ & $1.34 \pm 0.12^{* * \Delta}$ \\
\hline $\mathrm{Hb}$ & $12.94 \pm 0.39$ & $10.40 \pm 0.44^{* * \Delta}$ & $8.00 \pm 0.22^{* * \Delta}$ & $5.90 \pm 0.31^{* * \Delta}$ \\
\hline HCT & $24.82 \pm 0.34$ & $19.52 \pm 0.50^{* * \Delta}$ & $15.78 \pm 0.31^{* * \Delta}$ & $12.54 \pm 0.45^{* * \Delta}$ \\
\hline $\mathrm{MCV}$ & $62.97 \pm 1.85$ & $66.87 \pm 2.20^{* * \Delta}$ & $77.75 \pm 3.98^{* * \Delta}$ & $93.94 \pm 7.53^{* * \Delta}$ \\
\hline $\mathrm{MCH}$ & $32.82 \pm 0.70$ & $28.77 \pm 0.90$ & $39.37 \pm 0.49^{* *}$ & $44.26 \pm 4.86^{* *}$ \\
\hline $\mathrm{MCHC}$ & $52.15 \pm 1.46$ & $53.32 \pm 3.06$ & $50.73 \pm 2.41$ & $47.06 \pm 2.44^{* *}$ \\
\hline Platelets & $48.40 \pm 0.49$ & $55.24 \pm 0.49^{* * \Delta}$ & $61.34 \pm 0.99^{* * \Delta}$ & $68.08 \pm 0.58^{* * \Delta}$ \\
\hline Glucose Level & $60.02 \pm .191$ & $68.2 \pm 0.165^{* * \Delta}$ & $84.96 \pm 0.250^{* * \Delta}$ & $103.16 \pm 0.248^{* * \Delta}$ \\
\hline
\end{tabular}

Control intestine tissues: The light microscopy of intestine section of control group of $L$. rohita presented normal structure of villi with no alteration (Table 2; Fig. 3A-B). The histological architecture of intestinal villi consists of mucosal epithelium, lamina properia, muscularis mucosa, stratum compactum and serous membrane.

Treated intestine tissues: In treated group-I exposed to $0.50 \mathrm{ppb}$ of CYP, intestine showed mild alterations including goblet cells formation in villi and shortening of villi (Table 2; Fig. 3C-D). In treated group-II exposed to $1.00 \mathrm{ppb}$ concentration of CYP these histopathological alterations were moderate along with fusion of villi, necrosis, hemorrhages and pyknosis (Fig. 3E-F). In treated group-III exposed to $1.50 \mathrm{ppb}$ of CYP, the intestine showed severe histopathological changes (Table 2; Fig. 3G-H).

\section{Discussion}

The current investigation was conducted to understand the noxious level induced by commercial CYP pesticide on the hematological, histopathological and biochemical aspects of L. rohita. Overall, no mortality was witnessed during $96 \mathrm{~h}$ exposure. Because most of the pesticides influence the activity of acetylcholinesterase (AChE) consequently producing abnormal behavioral patterns in the fish. In our study, L. rohita was intoxicated with $0.50,1.00$ and $1.5 \mathrm{ppb}$ concentrations of CYP and various signs of behavioral distress like hyper-excitability, erratic and darting swimming, increased mucous secretion, loss of equilibrium, opening of gills and sinking to the bottom was observed in the treated group of Rohu. Hematological parameters are one of the most important biomarkers to examine the effects of pesticides on health of an organism (Lavanya et al., 2011). Pyrethroid pesticides causes significant alterations in hematological and histopathological parameters of fish (Velisek et al., 2009; Mahboob et al., 2017).

Hematological investigations have proved a valued tool for the fisheries experts to detect alterations in fish morphology and these alterations may lead to a change in behavior of fish and evident lacerations (Authman et al., 2015). In this study, significant changes were noticed in blood components of treated fish. These changes included reduction in the red blood cells count, $\mathrm{Hb}$ level, Hematocrit (HCT), mean corpuscular volume (MCV), mean corpuscular hemoglobin $(\mathrm{HCH})$ and mean corpuscular hemoglobin concentration (MCHC) values. On the other hand, certain components of blood were increased as a result of intoxication with CYP. These components include white blood cells and platelets count. The reduction in $\mathrm{Hb}$ and several other blood components might be due to the inhibition of RBCs' and haem synthesis, osmoregulatory dysfunction and destruction of RBCs in hematopoietic organs as reported earlier in Catla catla (Vani et al., 2011). Leukocytes play a significant role in regulation of immunological role and the variations in WBC counts after treatment with several toxicants may depict a decline in generic insusceptibility of the fish (Okomoda et al., 2013).

The substantial increment in leukocyte count in the current investigation may be attributed to general immune response and a defensive response of CYP. According to (Ndimele et al., 2015), hemoglobin, red blood cells, MCV and MCHC decreased significantly while WBC and Thrombocyte increased in Clarias gariepinus as a result of acute exposure to Endosulfan. Similarly, hematological examination reported by (Kavitha et al., 2012) revealed a significant reduction in $\mathrm{Hb}, \mathrm{HCT}, \mathrm{RBC}$ and $\mathrm{MCHC}$ levels in fish exposed to Moringa oleifera seed extract. Generally, reduction in hemoglobin level, hematocri, and number of red blood cells might be owing to erythroblastosis causing anemia (Saleh and Marie, 2016). Similar observations were also previously reported in $C$. gariepinus, which was exposed to tobacco leaf extracts, and cassava effluents (Adamu, 2009). White blood cells are the main components of the blood that shield the organism in the time of injury, hemorrhage and entry of foreign antigen particle in the body (Velmurugan et al., 2016). During stress, the number of leukocytes increases significantly to cope with conditions of stress and defend organism (Deshmukh, 2016). 

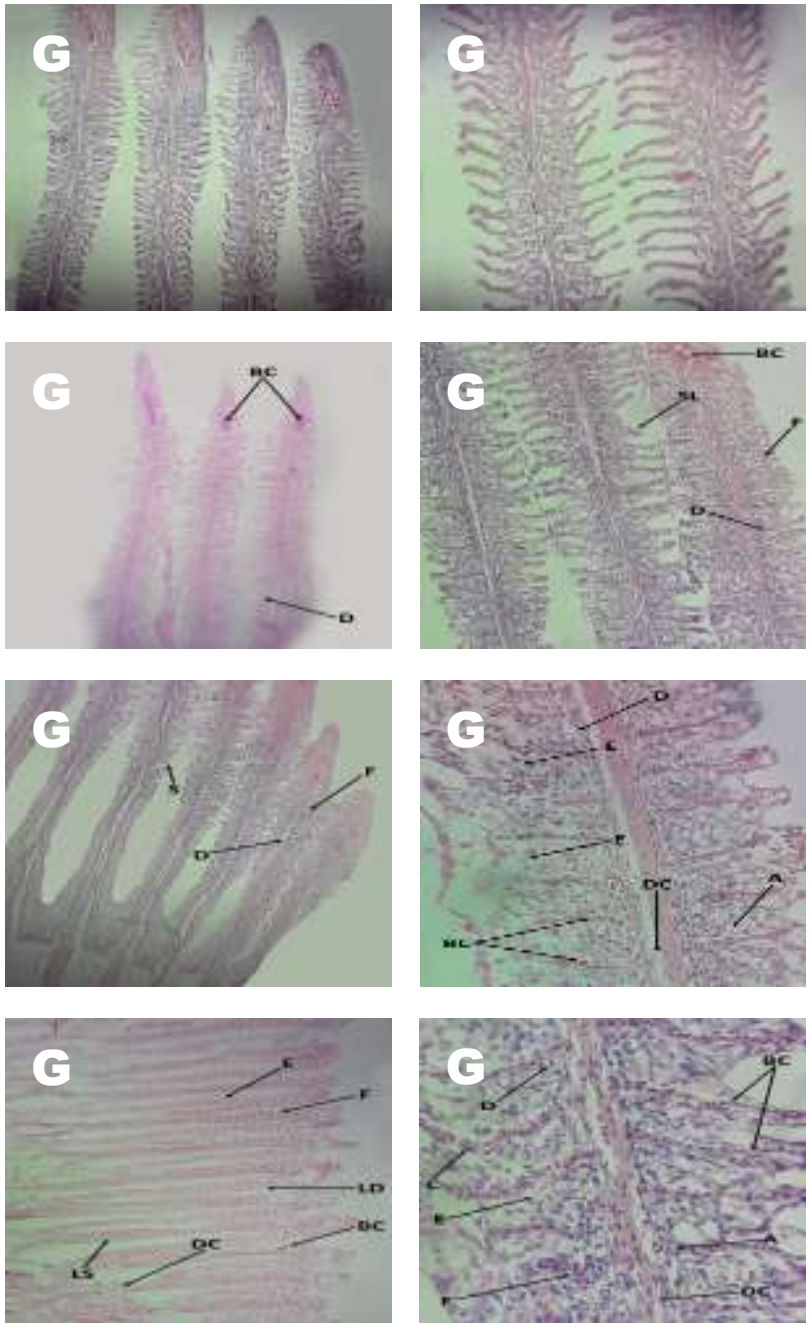

Fig. 1: A and B shows Gill structure of control fish while Gills tissues of treated fish $\mathrm{C}$ to $\mathrm{H}$ shows Epithelial lifting (E), Fusion of secondary gills lamellae (F), Lamellar disorganization (LD), Blood congestion (BC), Disruption of cartilaginous core (DC) and Shortening secondary gills lamellae (SL), Disruption of secondary gills lamellae (D), Curling (C) and Atrophy (A)

Thrombocytes are one of the indispensable component of blood playing major role in clotting of blood by absorbing various factors for blood clotting and delivering them to the site of injury of hemorrhage (Singh and Srivastava, 1981). Likewise, (Hasan et al., 2015), reported a significant increase in platelet number during acute toxicity of Grass carp when exposed to endosulfan.

A momentous surge in the blood glucose level was noticed in all the treated groups of $L$. rohita as compared to the control group. This result is in accordance with that of (Das and Mukherjee, 2003) who had also reported hyperglycemia in $L$. rohita upon exposure to CYP. Hyperglycemia in fish is a general secondary stress response to acute toxic effect and reliable sign of ecological stress.
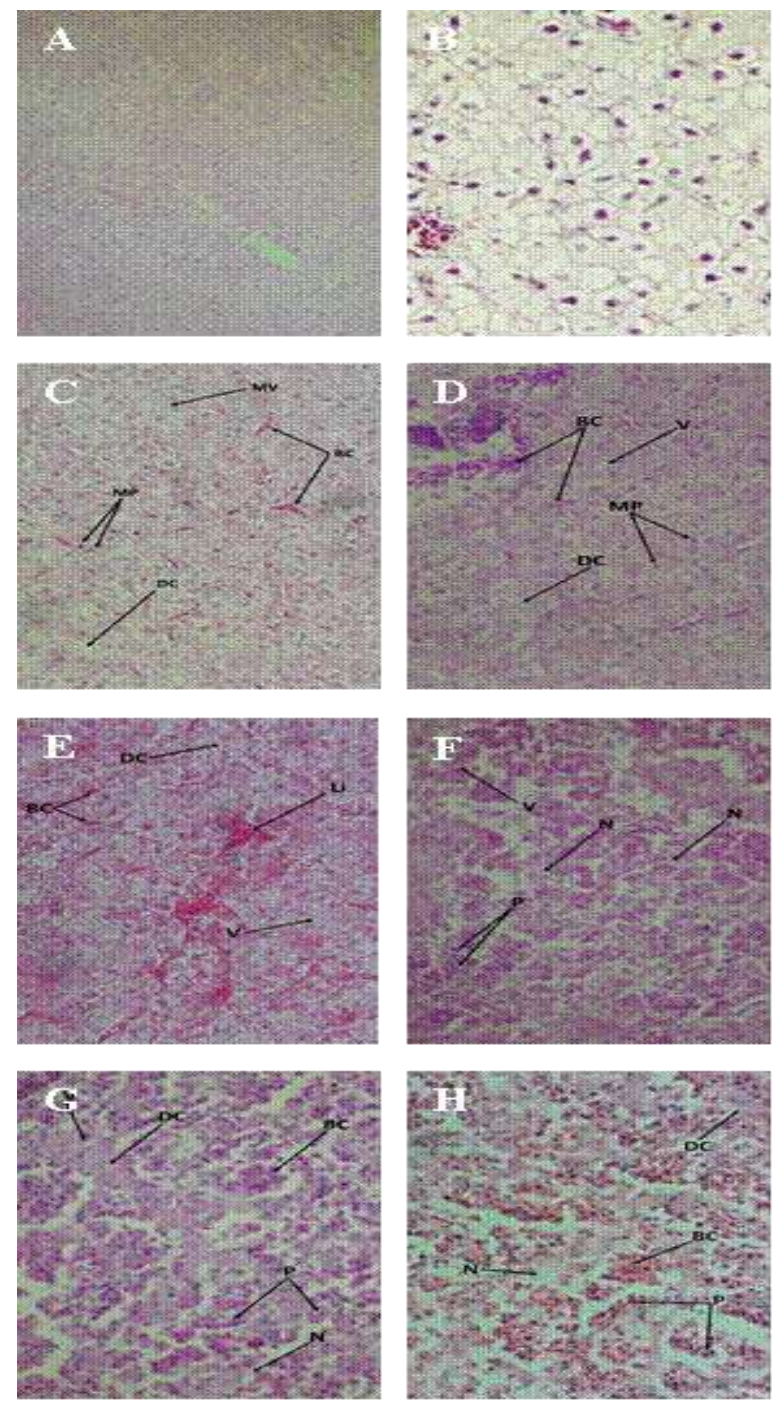

Fig. 2: A and B shows Liver structure of control fish while Liver tissues of treated fish $\mathrm{C}$ to $\mathrm{H}$ shows Dissolution of cell membrane (DC), Blood congestion (BC), Necrosis (N) and Pyknosis (P), Vacuolations in the hepatocytes (V), Lymphocyte infiltration (Li)

It enables the animal to cope with the condition of stress by making more energy available to vital organ as per demand (Suvetha et al., 2010). Same results was obtained by (Velisek et al., 2006) in rainbow trout exposed to acute CYP, showed significant increased level of alkaline phosphatase, ammonia, aspartate aminotransferase, lactate dehydrogenase, creatine kinase and glucose in blood plasma. Contrarily (Agrahari et al., 2007) who stated that Monocrotophos exposure induced hypoglycemia in Channa puntatus. Fish treated with lindane exhibited a substantial increase in plasma glucose level during the entire investigation related to the control groups (Saravanan et al., 2011). 

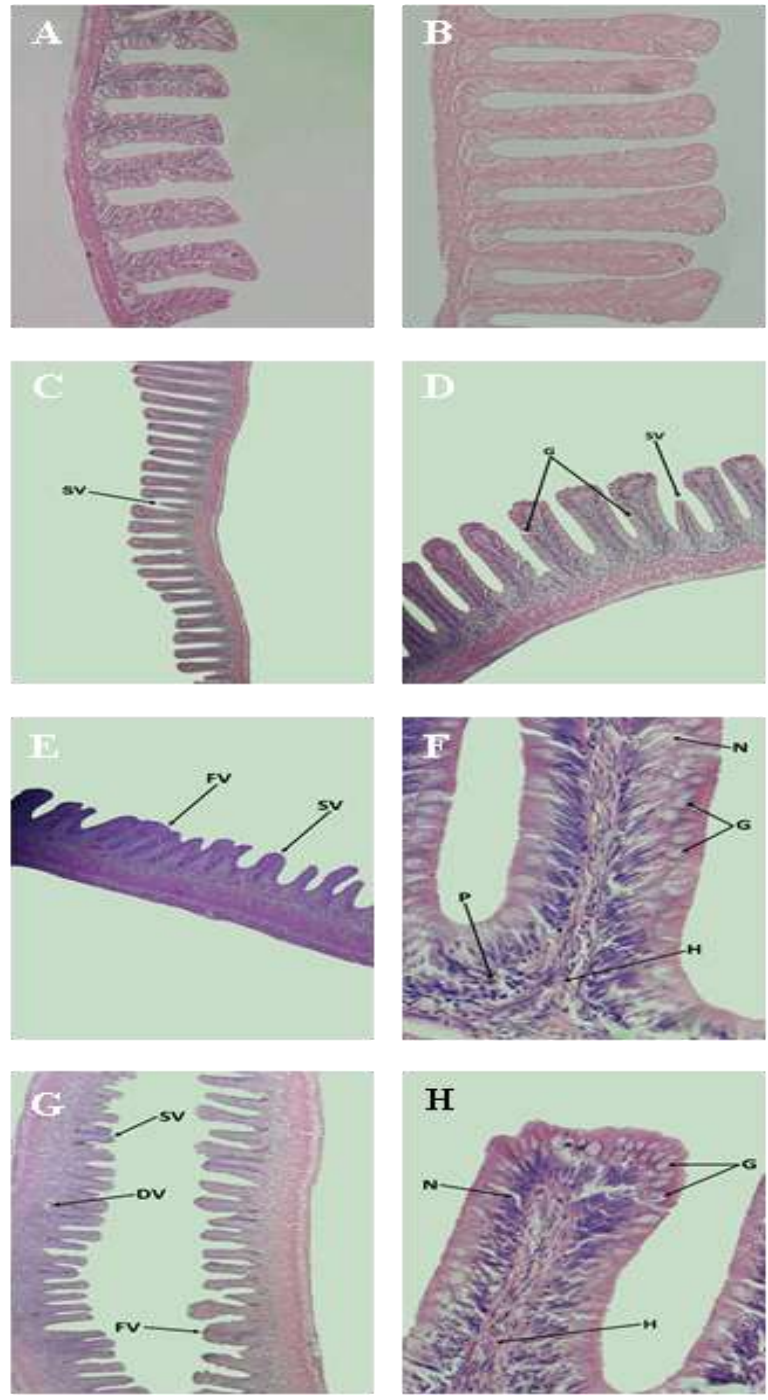

Fig. 3: A and B shows Intestine structure of control fish. Intestine tissues of treated fish $\mathrm{C}$ to $\mathrm{H}$ Shows Shortening of villi (SV), Goblet cells formation in villi (G) Fusion of villi $(\mathrm{F})$, Necrosis $(\mathrm{N})$, Hemorrhages $(\mathrm{H})$ and Pyknosis $(\mathrm{P})$, Detachment of villi (DV)

Various histopathological studies indicated that gills are the first target of fishes on exposure to pesticides and are prime indicators to show water quality (Qureshi et al., 2016). Gills beside absorbing oxygen perform many important functions such as regulation of ions, acid base balance and elimination of nitrogenous wastes from body. So, the ecological toxicants affect these vital organs severely and indirectly impose significant effects on health of fish (Bantu et al., 2017). In present study, various hematological alterations were noticed in gills of fish exposed to various concentrations of CYP. Among them prominent ones are lamellar disorganization, disruption of cartilage, epithelial lifting, loss, fusion, curling and shortening of secondary gills lamellae, atrophy and blood
Table 2: Summarized histopathological effects on gills, liver and intestine of both control group and groups exposed to various concentrations of cypermethrin

\begin{tabular}{llllll}
\hline Body parts & Histopathological alterations & E-0 & E-1 & E-2 & E-3 \\
\hline Gills & Lamellar disorganization & - & - & $*$ & $* * *$ \\
& Disruption of cartilaginous core & - & - & $* *$ & $* * *$ \\
& Blood congestion & - & $*$ & $* *$ & $* * *$ \\
& Disruption of Sec gills lamellae & - & $*$ & $* *$ & $* * *$ \\
& Epithelial lifting & - & - & $* *$ & $* * *$ \\
& Loss of secondary lamellae & - & - & $*$ & $* * *$ \\
& Fusion of Sec gills lamellae & - & $*$ & $* *$ & $* * *$ \\
& Shortening of Sec gills lamellae & - & $*$ & $* *$ & $* * *$ \\
& Atrophy & - & - & $* *$ & $* * *$ \\
& Curling & - & - & $*$ & $* * *$ \\
& Dissolution of cell membrane & - & $*$ & $* *$ & $* * *$ \\
Liver & Blood congestion & - & $*$ & $* *$ & $* * *$ \\
& Vacuolations in hepatocytes & - & $*$ & $* *$ & $* * *$ \\
& Hyperplasia & - & - & $* *$ & $* * *$ \\
& Pyknosis & - & $*$ & $* *$ & $* * *$ \\
& Necrosis & - & - & $* *$ & $* * *$ \\
& Lymphocyte infiltration & - & $*$ & $* *$ & $* * *$ \\
& Disruption of villi & - & - & $*$ & $* * *$ \\
& Fusion of villi & - & - & $* *$ & $* * *$ \\
& shortening of villi & - & $*$ & $* *$ & $* * *$ \\
& Goblet cells formation in villi & - & $*$ & $* *$ & $* * *$ \\
& Hemorrhages & - & - & $* *$ & $* * *$ \\
& Necrosis & - & - & $* *$ & $* * *$ \\
\hline & Rartine & & & &
\end{tabular}

Absent (-), Rare (*), Frequent (**), Abundant (***)

congestion. The extent of tissue damage increased as a result of exposure to increasing concentration of CYP. Several other investigations have revealed parallel impacts of pesticides on fish gills. Studies conducted by (Ghanbahadur and Ghanbahadur, 2012) showed that deterioration of secondary gill lamellae, necrosis of respiratory epithelium and devastation of primary gill lamellae is also evident after exposure of Rarbora daniconius to endosulfan pesticide. According to (Hasan et al., 2015) exposure of Ctenopharyngodon idella to endosulfan during acute toxicity results in blood mobbing, reduction in size and joining and fusion of both primary and secondary gills lamellae, epithelial lifting in the gills and hypertrophy. Histopathological alterations in gills of $L$. rohita during $96 \mathrm{~h}$ acute toxicity with CYP is same as the findings of toxicological impact of fungicide propiconazole on gill tissue including alterations such as desquamation of the epithelial lining, lamellar disorganization, hemorrhagic congestion and necrosis at the secondary lamellae (Tabassum et al., 2016). Different pesticides showed similar results in different fishes. For instance C. punctata exposed to pendimethalin showed cellular hypertrophy with loss in the epithelial layer, fusion of secondary lamellae, cellular degeneration, necrosis of gill epithelial tissues, epithelial lifting and blood congestion in the vascular axis of primary filaments (Tabassum et al., 2016), Cyprinus carpio exposure to buprofezin and fipronil (Qureshi et al., 2016). Arius thalassinus exposed to heavy metals (Saleh and Marie, 2016), Puntius ticto exposure to $5.012 \mathrm{ppm}$ of dimethoate (Marutirao, 2012), 
common carp (Pal et al., 2012) and C. punctatus (Devi and Mishra, 2013) exposed to Chlorpyrifos, resulting in ascending histopathological alterations with increasing various pesticides concentrations.

Liver is one of the vital organs in the body that plays a major role in carbohydrates, proteins and fats metabolism. It is also an organ for detoxifying harmful agents. Accumulation of most of the pesticides and their byproducts in hepatocytes results in significant histopathological modification and variation in liver (Sharma et al., 2012). In the current investigation, dissolution of cell membrane, blood mobbing and congestion, pyknosis, necrosis, hyperplasia and vacuolations of hepatocytes in L. rohita was noticed after exposure to CYP. (Murussi et al., 2016; Saleh and Marie, 2016). The histological modifications reveled in the liver of $C$. punctatus during present trials are in accordance to the results in Nile tilapia i.e., Oreochromis misniloticus (Coimbra et al., 2007) and rain bow trout i.e., Oncorhynchus mykiss (Altinok and Capkin, 2007) treated with varying concentrations of endosulfan, Common carp treated with chlorpyrifos (Pal et al., 2012), C. carpio treated with buprofezin fipronil (Qureshi et al., 2016). C. catla exposed to $\alpha$-CYP (Muthuviveganandavel et al., 2013).

Intestine is a prime part of fish digestive system, playing major role in digestion and assimilation of food materials. It is highly sensitive to any toxic material engulfed and can be used as an important biomarker organ for assessment of ecotoxicology. In this study, changes in intestinal tissues of $L$. rohita were predominantly necrosis, hemorrhages, overproduction of goblet cells in villi, fusion, detachment and shortening of villi as reported earlier by (Hasan et al., 2015), for acute endosulfan toxicity exposure. The deterioration of villi, mucosal folds disintegration, vacuolations, hypertrophy, and necrosis in $C$. carpio and Cirrhinus mrigala treated with atrazine and fenvalerate, was observed (Velmurugan et al., 2007). Severe mucosal secretion occurs due to distress enabling fish to cope with ecological stress (Samanta et al., 2016). Leukocytes infiltration, necrosis in gut tissues in Mosquito fish, Gambusia affinis treated with deltamethrin (Cengiz and Unlu, 2006); Intestinal lesions, eosinophils invasion into the lamina properia and epithelial cells atrophy was observed in C. mrigala exposed to lambda-cyhalothrin for 60 days, which showed shortening of villi with inflammation, rupture of cells, degeneration changes in tips of villi, curved villi, hemorrhage, necrosis, numerous vacuoles, dilation in the blood vessels, completely damaged villi and loss of architecture in a number of fish species (Cengiz and Unlu, 2006; Velmurugan et al., 2007; Vidhya and Nair, 2016).

\section{Conclusion}

This study unraveled the toxic effects of commercial CYP formulation on behavior, hematology, histopathology and biochemical (glucose) parameters of freshwater fish L. rohita. The present study could be useful to access the previously unanticipated possible environmental hazards of CYP to aquatic life. In summary, this study suggested that CYP significantly increased WBCs, Platelets and Blood Glucose Level whereas it resulted in decreased $\mathrm{RBCs}, \mathrm{Hb}, \mathrm{HCT}, \mathrm{MCV}, \mathrm{MCH}$ and $\mathrm{MCHC}$ values. It significantly affected the histopathology like lamellar disorder, disruption of cartilage, epithelial lifting, blood congestion, damage, fusion, twisting, shortening, degeneration of secondary gills lamellae and atrophy in gills, dissolution of cell membrane, pyknosis, blood congestion, necrosis, hyperplasia and vacuolations in liver and necrosis, hemorrhages, over production of goblet cells, disintegration, fusion and shortening of villi in intestine, respectively.

\section{References}

Adamu, K.M., 2009. Sublethal effects of tobacco (Nicotiana tobaccum) leaf dust on enzymatic activities of Heteroclarias (a hybrid of Heterobranchus bidorsalis and Clarias gariepinus). Jord. J. Biol. Sci., 2: 151-158

Agrahari, S., K.C. Pandey and K. Gopal, 2007. Biochemical alteration induced by monocrotophos in the blood plasma of fish, Channa punctatus (Bloch). Pest. Biochem. Physiol., 88: 268-272

Altinok, I. and E. Capkin, 2007. Histopathology of rainbow trout exposed to sublethal concentrations of methiocarb or endosulfan. Toxicol. Pathol., 35: 405-410

Amin, K.A. and K.S. Hashem, 2012. Deltamethrin-induced oxidative stress and biochemical changes in tissues and blood of catfish (Clarias gariepinus): antioxidant defense and role of alpha-tocopherol. BMC Vet. Res., 8: 45

Athanassopoulou, F., I. Pappas and K. Bitchava, 2009. An overview of the treatments for parasitic disease in Mediterranean aquaculture. Options Méditerr. Ser A, 86: 65-83

Authman, M.M., M.S. Zaki, E.A. Khallaf and H.H. Abbas, 2015. Use of fish as bio-indicator of the effects of heavy metals pollution. J. Aquat. Res. Dev., 6: 1

Bantu, N., N. Kumari and R. Vakita, 2017. Histological Alteration in Different Tissues of Indian major carp, Labeo rohita (Hamilton) exposed to Profenofos 50\% EC and Carbosulfan 25\% EC formulations. J. Biol. Today World, 6: 38-45

Barata, C., M. Medina, T. Telfer and D. Baird, 2002. Determining demographic effects of cypermethrin in the marine copepod Acartia tonsa: stagespecific short tests versus life-table tests. Arch. Environ. Contam. Toxicol., 43: 0373-0378

Boxaspen, K. and J.C. Holm, 2001. The development of pyrethrum- based treatments against the ectoparasitic salmon lice Lepeophtheirus salmonis in sea cage rearing of atlantic salmon Salmo salar L. Aquacult. Res., 32: 701-707

Bradbury, S.P. and J.R. Coats, 1989. Comparative toxicology of the pyrethroid insecticides. Rev. Environ. Contam. Toxicol., Springer, The Netherlands

Carriquiriborde, P., J. Díaz, H. Mugni, C. Bonetto and A.E. Ronco, 2007. Impact of cypermethrin on stream fish populations under field-use in biotechsoybean production. Chemosphere, 68: 613-621

Casida, J.E., D.W. Gammon, A.H. Glickman and L.J. Lawrence, 1983. Mechanisms of selective action of pyrethroid insecticides. Annu. Rev. Pharmacol. Toxicol., 23: 413-438

Cengiz, E.I. and E. Unlu, 2006. Sublethal effects of commercial deltamethrin on the structure of the gill, liver and gut tissues of mosquitofish, Gambusia affinis: a microscopic study. Environ. Toxicol. Pharmacol., 21: 246-253

Coimbra, A.M., A. Figueiredo-Fernandes and M.A. Reis-Henriques, 2007. Nile tilapia (Oreochromis niloticus), liver morphology, CYP1A activity and thyroid hormones after endosulfan dietary exposure. Pest. Biochem. Physiol., 89: 230-236

Das, B.K. and S.C. Mukherjee, 2003. Toxicity of cypermethrin in Labeo rohita fingerlings: biochemical, enzymatic and haematological consequences. Comparative Biochem. Physiol. Part C: Pharmacol. Toxicol., 134: 109-121

Deshmukh, D., 2016. Hamatological response in a freshwater fish Channa Striatus exposed to endosulfan pesticide. Biosci. Discov., 7: 67-69 
Devi, Y. and A. Mishra, 2013. Histopathological alterations in gill and liver anatomy of fresh water, air breathing fish Channa punctatus after pesticide Hilban ${ }^{\circledR}$ (Chlorpyrifos) treatment. Adv. Bioresour., 4: 57-62

Dhanakumar, S., G. Solaraj and R. Mohanraj, 2015. Heavy metal partitioning in sediments and bioaccumulation in commercial fish species of three major reservoirs of river Cauvery delta region, India. Ecotoxicol. Environ. Saf., 113: 145-151

Eagles-Smith, C.A. and J.T. Ackerman, 2014. Mercury bioaccumulation in estuarine wetland fishes: Evaluating habitats and risk to coastal wildlife. Environ. Pollut., 193: 147-155

Ghanbahadur, A. and G. Ghanbahadur, 2012. Histopathological effect of organochloride endosulphan on intestine and stomach of larvivorous fish Rasbora daniconius. Res. Rev. J. Zool. Sci., 4: 28-33

Hasan, Z., S. Ghayyur, Z.U. Hassan and S. Rafique, 2015. Histomorphometric and hematological profile of grass carp (Ctenopharyngodon idella) during acute endosulfan toxicity. Pak. Vet. J., 35: 23-27

Haya, K., 1989. Toxicity of pyrethroid insecticides to fish. Environ. Toxicol. Chem., 8: 381-391

Huang, B., B. Wang, D. Ren, W. Jin, J. Liu, J. Peng and X. Pan, 2013. Occurrence, removal and bioaccumulation of steroid estrogens in Dianchi Lake catchment, China. Environ. Int., 59: 262-273

John, P. and A. Prakash, 2003. Bioaccumulation of pesticides on some organs of freshwater catfish Mystus vittatus. Bull. Environ. Contam. Toxicol., 70: 1013-1016

Kavitha, C., M. Ramesh, S.S. Kumaran and S.A. Lakshmi, 2012. Toxicity of Moringa oleifera seed extract on some hematological and biochemical profiles in a freshwater fish, Cyprinus carpio. Exp. Toxicol. Pathol., 64: 681-687

Khan, B.A., A. Farid, N. Khan, K. Rasul and K. Perveen, 2006. Survey of pesticide use on fruits and vegetables in district Peshawar. Sarhad J. Agric., 22: 497

Lavanya, S., M. Ramesh, C. Kavitha and A. Malarvizhi, 2011. Hematological, biochemical and ionoregulatory responses of Indian major carp Catla catla during chronic sublethal exposure to inorganic arsenic. Chemosphere, 82: 977-985

Mahboob, S., S. Sultana, K.A. AlGhanim, F. Al-Misned, T. Sultana, B. Hussain and Z. Ahmed, 2017. Distribution and accumulation of polychlorinated biphenyls (PCB), polycyclic aromatic hydrocarbons (PAHs) and organo-chlorine residues in the muscle tissue of Labeo rohita. Int. J. Agric. Biol., 19: 701-706

Marigoudar, S.R., R.N. Ahmed and M. David, 2009. Cypermethrin induced respiratory and behavioural responses of the freshwater teleost, Labeo rohita (Hamilton). Vet. Arch., 79: 583-590

Marutirao, G.R., 2012. Histopathological changes in the gills of Puntius ticto (Ham) under Dimethoate toxicity. Bioscan, 7: 423-426

Medina, M., C. Barata, T. Telfer and D. Baird, 2002. Age-and sex-related variation in sensitivity to the pyrethroid cypermethrin in the marine copepod Acartia tonsa Dana. Arch. Environ. Contam. Toxicol., 42: 17-22

Murussi, C.R., M.D. Costa, J.W. Leitemperger, L. Guerra, C.C. Rodrigues, C.C. Menezes, E.S. Severo, F. Flores-Lopes, J. Salbego and V.L. Loro, 2016. Exposure to different glyphosate formulations on the oxidative and histological status of Rhamdia quelen. Fish Physiol. Biochem., 42: $445-455$

Muthuviveganandavel, V., I. Hwang, V. Anita, P.S. Malarani, C. Selvam, M. Hemalatha and M. Pandurangan, 2013. Synthetic Pyrethroid effect on blood plasma biomarker Enzymes and histological changes in Catla catla. Int. J. Exp. Pathol., 94: 104-108

Nafees, M. and M. Jan, 2009. Residues of cypermethrin and endosulfan in soils of Swat valley. Soil Environ., 28: 113-118

Ndimele, P., A. Jenyo-Oni, C. Kumolu-Johnson, K. Chukwuka and S. Onuoha, 2015. Effects of Acute Exposure to Endosulfan (Organochlorine Pesticides) on Hematology of African Mud Catfish, Clarias gariepinus. Bull. Environ. Contam. Toxicol., 95: 164-170

Okomoda, V., G. Ataguba and V. Ayuba, 2013. Hematological response of Clarias gariepinus fingerlings exposed to acute concentrations of Sunsate ${ }^{\circledR}$. J. Stress Physiol. Biochem., 9: 271-278

Pal, S., E. Kokushi, J. Koyama, S. Uno and A.R. Ghosh, 2012. Histopathological alterations in gill, liver and kidney of common carp exposed to chlorpyrifos. J. Environ. Health Sci. Part B., 47: 180-195
Qureshi, I.Z., A. Bibi, S. Shahid and M. Ghazanfar, 2016. Exposure to subacute doses of fipronil and buprofezin in combination or alone induces biochemical, hematological, histopathological and genotoxic damage in common carp (Cyprinus carpio L.). Aquat. Toxicol., 179: 103-114

Saleh, Y.S. and M.-A.S. Marie, 2016. Use of Arius thalassinus fish in a pollution biomonitoring study, applying combined oxidative stress, hematology, biochemical and histopathological biomarkers: A baseline field study. Mar. Pollut. Bull., 106: 308-322

Samanta, P., S. Pal, A.K. Mukherjee, D. Kole and A.R. Ghosh, 2016. Histopathological study in stomach and intestine of Anabas testudineus (Bloch, 1792) under Almix exposure. Fish Aqua J., 7: $1-7$

Saravanan, M., K.P. Kumar and M. Ramesh, 2011. Haematological and biochemical responses of freshwater teleost fish Cyprinus carpio (Actinopterygii: Cypriniformes) during acute and chronic sublethal exposure to lindane. Pestic. Biochem. Physiol., 100: 206-211

Sharma, V., D. Anderson and A. Dhawan, 2012. Zinc oxide nanoparticles induce oxidative DNA damage and ROS-triggered mitochondria mediated apoptosis in human liver cells (HepG2). Apoptosis, 17: $852-870$

Singh, N.N. and A.K. Srivastava, 1981. Effects of endosulfan on fish carbohydrate metabolism. Ecotoxicol. Environ. Saf., 5: 412-417

Song, Y., B. Salbu, L.S. Heier, H.-C. Teien, O.-C. Lind, D. Oughton, K. Petersen, B.O. Rosseland, L. Skipperud and K.E. Tollefsen, 2012. Early stress responses in Atlantic salmon (Salmo salar) exposed to environmentally relevant concentrations of uranium. Aquat. Toxicol., 112: $62-71$

Srivastava, N. and N. Kaushik, 2001. Use of fish as bioindicator of aquatic pollution. Proceedings Int. Congress Chem. Environ., pp: 23-27. Indore, India

Suvetha, L., M. Ramesh and M. Saravanan, 2010. Influence of cypermethrin toxicity on ionic regulation and gill $\mathrm{Na}^{+} / \mathrm{K}^{+}$-ATPase activity of a freshwater teleost fish Cyprinus carpio. Environ. Toxicol. Pharmacol., 29: 44-49

Tabassum, H., A.Q. Dawood, P. Sharma, J. Khan, S. Raisuddin and S. Parvez, 2016. Multi-organ toxicological impact of fungicide propiconazole on biochemical and histological profile of freshwater fish Channa punctata Bloch. Ecol. Indic., 63: 359-365

Vani, T., N. Saharan, S. Mukherjee, R. Ranjan, R. Kumar and R. Brahmchari, 2011. Deltamethrin induced alterations of hematological and biochemical parameters in fingerlings of Catla catla (Ham.) and their amelioration by dietary supplement of vitamin C. Pestic. Biochem. Physiol., 101: 16-20

Velisek, J., Z. Svobodova and V. Piackova, 2009. Effects of acute exposure to bifenthrin on some haematological, biochemical and histopathological parameters of rainbow trout (Oncorhynchus mykiss). Vet. Med., 54: 131-137

Velisek, J., T. Wlasow, P. Gomulka, Z. Svobodova, R. Dobsikova, L. Novotny and M. Dudzik, 2006. Effects of cypermethrin on rainbow trout (Oncorhynchus mykiss). Vet. Med., 51: 469

Velmurugan, B., E.I. Cengiz, P. Senthilkumaar, E. Uysal and A. Satar, 2016. Hematological parameters of freshwater fish Anabas testudineus after sublethal exposure to cypermethrin. Environ. Pollut. Prot., 1: 32-39

Velmurugan, B., M. Selvanayagam, E.I. Cengiz and E. Unlu, 2007. Histopathology of lambda-cyhalothrin on tissues (gill, kidney, liver and intestine) of Cirrhinus mrigala. Environ. Toxicol. Pharmacol., 24: 286-291

Vidhya, V. and C.R. Nair, 2016. International Journal of Advanced Research in Biological Sciences. Int. J. Adv. Res. Biol. Sci., 3: 43-47

Viran, R., F.Ü. Erkoç, H. Polat and O. Koçak, 2003. Investigation of acute toxicity of deltamethrin on guppies (Poecilia reticulata). Ecotoxicol. Environ. Saf., 55: 82-85

Zhao, X., X. Ren, R. Zhu, Z. Luo and B. Ren, 2016. Zinc oxide nanoparticles induce oxidative DNA damage and ROS-triggered mitochondria-mediated apoptosis in zebrafish embryos. Aquat. Toxicol., 180: 56-70

(Received 31 August 2017; Accepted 11 November 2017) 